\title{
Proficient Readers' Reading Behavior in Taiwan: The Study of Young Chinese Readers
}

\author{
Li-Chun Chang
}

Department of Early Childhood Education, National University of Tainan, Taiwan

Copyright $(2015$ Horizon Research Publishing All rights reserved.

\begin{abstract}
The purpose of this study was to explore the reading behavior of young proficient Chinese readers at preschool age. Especially, the roles of phonetic skill and Chinese Character recognition in reading comprehension were explored. 10 kindergartens were recruited to participate in the study. Subjects were 72-98 kindergarten children. Instruments include 5 measures of language assessments. Pearson product-moment correlation, ANOVA and stepwise regression were used to analyze quantitative data. Reading miscue analysis was employed to analyze children's reading style and error patterns. The results found: (1) Word recognition was a better predictor in reading fluency when comparing with Chinese phonic spelling ability. (2) Reading fluency was positively correlated with reading comprehension. (3) There were 4 types of young readers. (4) Balanced readers had the best reading comprehension abilities.(5) Young children used mostly syntax and semantics clues in miscue analysis. (6) Reading fluency and PPVT were the two best early predictors for later reading comprehension abilities.
\end{abstract}

Keywords Young Children, Proficient Readers, Reading Comprehension, Miscue Analysis

\section{Introduction}

Whether to learn Zhuyin Fuhao (Taiwan's phonetic symbol) in preschool stage for young children has been a controversial issue in Taiwan. Proponents believe that they help children to decode new words and to become a better reader, while opponents argue that reading is not just about decoding. Being able to correctly recite a passage does not mean the child is able to comprehend the text. Since Chinese characters are logograms in writing, word-sound connections are weak. Children should start their early reading practice by learning Chinese character directly.

Similar controversy was found in English speaking countries. In countries that speak alphabetic languages, especially in English speaking countries, views on reading acquisition has been the focus of many scholarly debates.
The two main rival views are the whole language approach and the skill-based approach. Both views agree that readers in the reading process will apply three kinds of language cues: semantic cues, grammatical cues and graphophonic cues. However, the two views on which cue is more important and leads to better reading abilities are totally different [4]. Between the two competing views, a third point of view emerged, the balance reading view [5]. The following will discuss the main arguments and major proponents of the three viewpoints.

\section{Reading Acquisition Theories}

(A) The whole language approach

Whole language advocates, such as Yetta Goodman and Ken Goodman [11], believe that readers apply all three language cues to help them understand the text, Goodman, Watson, Burke [12] argue that the semantic cues are the deep structure, and graphophonic cues are the surface structure in the reading process. Proficient readers rely more on semantic and grammatical cues; on the contrary, poor readers depend more on graphophonic cues.

\section{(B)The skill-based approach}

The skill-based approach views language as an object instead of as a process. It can be acquired by breaking into smaller parts and recombining the parts into larger units. Supporters of skill-based view emphasize the role of graphophonic cues in the reading process. Wren [27] points out only poor reader use multiple cues to decode while good readers are able to decode words quickly and automatically without depending on sematic or syntactic cues. Adams [1] also believes that the use of graphophonic cues is an important indicator to distinguish successful readers, independent readers and readers with dyslexia. Eldredge [8] finds the spelling ability playing an important role in word recognition and reading fluency.

(C) The balance view approach

Speigel [19] first proposes a blending of the two approaches (skill and whole language) to teach reading. In Cassidy and Ortlieb's [6] survey, they define that balance 
reading program as containing elements of skills instruction with high quality of literature. Farrington [7] thinks that young readers should be taught phonics and high frequency words as a priority. However, Farrington [7] also proposes that children need to learn how to tackle new words, especially those that are irregular, by using a range of cuing strategies as to enhance their confidence as readers. Therefore, Farrington [7] do not agree that fixing on a method of teaching is the best, instead that the balanced application of the two methods should be used.

\section{Early Reading behavior Studies and Miscue Analysis}

Research approaches since the 1980s on early reading behaviors can be divided into two categories, one category focuses on the parent-child or teacher-child shared-reading studies. This line of researches focus on the analysis of verbal and non-verbal information reading content [e.g. $3,7,13,14,17,20,24]$. Another category of research explores young children's independent reading behaviors and functions [e.g.14,18,20,21]. After 1980s, the focus of researches shifts to analyzing content in order to establish theories of language development. After 1990s, the focus of researches turns to exploring the strategies young readers used during the reading process.

Miscue analysis was first coined by Goodman in 1969. Goodman believes that mistakes made by readers when reading a text are not necessarily bad, instead they are" windows on the reading process [10]. The pattern of miscues can be used to analyze the strengths and weaknesses of a reader. From 1969-1996, hundreds of research papers about reading miscues have been published [4]. However, recent studies in the decade focused on young children are very rare. For example, Kabuto [15] investigated a case study on a third grader's reading difficulties and his mother's use of retrospective miscue analysis strategies. Almazrout [2] also conducted a case study by using MRA to explore a third grader who speaks Arabic and English on his bilingual reading behaviors. Only one miscue study was found in Taiwan's published journals, Wang [26] explored a group of third-graders with reading difficulties. The study found reading accuracy has no positive relationship with reading comprehension. Miscue analysis found that "omit" and "close-sound replacement" was used most frequently.

Based on the controversy on the reading approach and scarcity of researches on young Chinese readers' miscue analysis, the purposes of the present study are as follows:

1. The study will explore the relationship among phonetic skills, word recognition, reading fluency, correct rate and incorrect words.

2. The study will identity young readers' reading strategies, categorize different types of readers and its relationship to reading comprehension.

3. The study will analyze miscue patterns of young Chinese readers.

4. The study will find out which skills are better predictors for reading comprehension.

\section{Method}

\section{Participants}

Subjects came from 10 kindergartens in Tainan city, Taiwan. The proficient readers were recommended by their kindergarten teachers. In the first stage, there were 98 kindergarteners, 44 boys and 54 girls. In the second stage, there were 81 kindergarteners, 37 boys and 44 girls. In the third stage, there were 72 kindergarteners, 33 boys and 39 girls. The mean age of participants was 5.7 years old, with ages ranging from 4-6 years old.

\section{Materials}

Five instruments were employed to test different aspects of children's language abilities.

Chinese Character Recognition Test (Character Recognition). This standardized test includes 200 Chinese characters. The ordering of characters depends on word frequency ranged from high to low. In this study, only the first 100 characters were used. Children were asked to circle the characters they knew and the test administer asked the child to read the word sound out. One point was given for one correct pronunciation.

Zhuyin Fuhao (Taiwan's phonetic symbol) Spelling Test(Phonetic Skill). The $10^{\text {th }}$ chapter of "The Magic book of Bo Po Mo" was used. One point was given for one correct sound combination.

Peabody Picture Vocabulary Test-Chinese Version(PPVT). The Chinese Version PPVT was standardized by Taiwanese researchers using Taiwanese sample to established Taiwanese norm. The Chinese PPVT is used for children aged from 3-12. Form A was used in this study.

Storybook Read Aloud and Comprehension Test. Seven storybooks were selected. The principle for selection was based on story structure, with/without Taiwan phonetic symbols, vertical/horizontal word print style. Five comprehension questions were asked immediately after a child finished reading a story.

\section{Procedure}

The study was divided into 3 stages. In the first stage, the research assistant came to the kindergarten to test potential subjects with spelling test and Chinese character recognition test. The assistant invited the child to read his/her favorite picture book. The whole process was audio- and video-taped. Reading fluency, correct rate and incorrect word pronunciation were calculated.

In the second stage, selected subjects considered as early proficient readers were administered with PPVT test, and asked to read four assigned picture books. After reading each book, subjects were immediately asked five comprehension questions. The whole process was also audio-and video-taped. Reading fluency, correct rate, incorrect word pronunciation and comprehension score were calculated.

In the third stage, subjects entered to the second stage were followed four months later. Sample attrition was 
inevitable due to transferring to another institution or unwillingness to participate in the study again. Those who entered the third stage were asked to read two picture books and one story without pictures. Again, audio- and video-taping were utilized, and reading fluency, correct rate, incorrect word pronunciation and comprehension scores were calculated.

\section{Results}

\section{The Relationship between Phonetic Skills, Characters Recognition, and Reading Fluency, Correct rate, and Incorrect Word Pronunciation}

Table 1 shows that phonetic skill and character recognition was significantly related $(r=.270)$, but the correlation is not high. It is worth to note that characters recognition has moderately significant correlation with reading fluency $(\mathrm{r}=.661)$, but no significant correlation with phonetic skill. Reading accuracy has both significant correlation $(\mathrm{r}=.434, \mathrm{r}=.529)$ with phonetic skill and characters recognition, but the correlation value for characters recognition was higher. Incorrect word pronunciation was negatively correlated with phonetic skill, characters recognition, reading fluency and correct rate.

\section{The Relationship between Phonetic Skills, Characters Recognition, PPVT, and Reading Comprehension}

Table 2 shows that characters recognition is the best predictor to reading comprehension. Four picture books' reading comprehension was significantly correlated with characters recognition. Only two picture books' phonetic skill was significantly correlated with reading comprehension and the correlation value is very low. PPVT did not have any prediction power. This result seems to validate the notion that the preschool stage should not place undue emphasis on phonetic learning, but the ability to recognize and read words.

\section{Reading Styles and Reading Comprehension}

According to the miscue analysis, the study identified four types of readers: the phonetic symbol reader, the Chinese character reader, the balanced reader and the picture reader. One way ANOVA was conducted to find a significant difference in reading comprehension, and post hoc comparison, Scheffé's method, was employed to compare between groups. The results found that four books had significant differences. The results indicated that balanced readers performed best in reading comprehension, whereas the picture readers had a lowest reading comprehension performance.

\section{Miscue Analysis}

As a logographic writing system, the word-sound connection in Chinese is weak. In this part, only six books were analyzed, because Book 7 was a non-picture book and only a few of the readers were able to complete the task. According to the data collected, the researchers found that graphophonic cues should be divided into graphic cues and phonic cues. Also, the study identified vocabulary cues which were also unique in Chinese language. The results found that young readers used most were syntax and semantic cues (See Table 3) .

Table 1. Correlations among skill variables and outcome variables in reading fluency, rate, and incorrect words

\begin{tabular}{cccccc}
\hline & 1 & 2 & 3 & 4 & 5 \\
\hline 1.Phonetic skill & 1 & & & & \\
2.Characters Recognition & $.270^{* *}$ & 1 & & & \\
3.Reading fluency & .156 & $.661^{* *}$ & 1 & 1 & 1 \\
4.correct rate & $.434^{* *}$ & $.529^{* *}$ & $.631^{* *}$ & $-.930^{* *}$ & 1 \\
5.incorrect word & $-.385^{* *}$ & $-.484^{* *}$ & $-.592^{* *}$ & \\
\hline
\end{tabular}

$* * \mathrm{P}<.01$

Table 2. Correlations among skill variables and reading comprehension for 7 books

\begin{tabular}{cccccccc}
\hline & Book1 & Book2 & Book3 & Book4 & Book5 & Book6 & Book7 \\
\hline Phonetic skill & -.103 & -.079 & .240 & $.297^{*}$ & $.319^{* *}$ & .182 & .015 \\
Character Recognition & -.073 & -.029 & $.575^{* *}$ & $.519^{* *}$ & $.562^{* *}$ & $.330^{* * *}$ & -.027 \\
PPVT & .161 & .148 & .196 & -.151 & -.173 & -.119 & .136 \\
\hline
\end{tabular}

$* \mathrm{p}<.05, \quad * * \mathrm{P}<.01, * * * \mathrm{p}<.001$

Table 3. Miscue percentage

\begin{tabular}{cccccccc}
\hline Miscue & semantics & syntax & graphic & phonic & vocabulary & Give-up & other \\
\hline Book 1 & 21.40 & 43.41 & 3.04 & 7.09 & 3.36 & 19.03 & 2.67 \\
Book 2 & 22.19 & 37.31 & 1.62 & 14.05 & 3.38 & 18.26 & 3.18 \\
Book 3 & 33.56 & 41.88 & .91 & 9.04 & 1.14 & 14.85 & 1.16 \\
Book 4 & 19.93 & 44.77 & 1.87 & 4.01 & 7.14 & 20.41 & 4.30 \\
Book 5 & 13.20 & 20.37 & 4.80 & 4.75 & 4.25 & 46.48 & 6.09 \\
Book 6 & 14.41 & 29.14 & 4.43 & .66 & 7.80 & 28.28 & 15.74 \\
\hline
\end{tabular}


Table 4. Reading fluency, correct rate, incorrect word and reading comprehension analysis

\begin{tabular}{cccccccc}
\hline & Book 1 & Book2 & Book 3 & Book 4 & Book5 & Book6 & Book 7 \\
\hline Reading fluency & -.069 & $-.457^{* *}$ & $-.395^{*}$ & $-.385^{*}$ & $.520^{* *}$ & $.280^{*}$ & .003 \\
correct rate & -.043 & -.047 & $-.365^{*}$ & $-.335^{*}$ & $.436^{* *}$ & .053 & .070 \\
incorrect word & -.276 & $-.662^{* *}$ & $-.502^{* *}$ & $-.555^{* *}$ & $-.436^{* *}$ & -.195 &.-074 \\
\hline
\end{tabular}

Table 5. Reading fluency, correct rate, incorrect word and reading comprehension reanalysis

\begin{tabular}{cccccccc}
\hline & Book1 & Book2 & Book3 & Book4 & Book5 & Book6 & Book7 \\
\hline Reading fluency & .277 & $.431^{* *}$ & $.379^{*}$ & $.452^{*}$ & $.408^{* *}$ & $.295^{*}$ & $.440^{* *}$ \\
correct rate & .276 & -.092 & $.250^{*}$ & $.476^{*}$ & $.374^{*}$ & .037 & $.356^{*}$ \\
incorrect word & -.276 & $-.487^{* *}$ & -.249 & $-.444^{* *}$ &.$- .371^{*}$ & -.171 & $-.349^{*}$ \\
\hline
\end{tabular}

Table 6. Stepwise Regression analysis

\begin{tabular}{cccccc}
\hline & B & SE & Beta & $\mathrm{t}$ & $\mathrm{p}$ \\
\hline Model 1 $\left(R^{2=.344}\right)$ & & & & & \\
Reading Fluency & 1.076 & 2.81 & .587 & 3.832 & .001 \\
Model 2 $\left(R^{2=.448}\right)$ & & & & & \\
Reading Fluency & 9.63 & .267 & .525 & 3.607 & .001 \\
PPVT & .028 & .012 & .329 & 2.258 & .032 \\
\hline
\end{tabular}

\section{The Relationship between Reading Fluency, Correct Rate and Reading Comprehension}

The researchers found a very interesting phenomenon in the study. When the researcher included all types of readers in the analysis, it was found that reading comprehension and reading fluency were significantly negatively correlated (See Table 4). This result discovered that the slower a child reads, the better his/her comprehends. This interpretation is contradictory to what we have known and is inconsistent to related literature results. Therefore, the researcher speculated this confounding result was influenced by including picture readers in the analysis. In the first stage, the selected picture books were easy. Picture readers flipped through the book quickly and were able to understand the story through pictures within a very short time. Thus, the researcher removed the picture reader group and reanalyzed the data. The findings were now consistent with previous interpretations. Six picture books' reading comprehension and reading fluency were significantly positive correlated. It indicated that the faster a child reads, the better he/she comprehend (Table 5). Only Book 1 was not significantly correlated, and this result was attributed to the text style of the book. The book is a postmodern narration. There are two story lines presented simultaneously. This could be quite difficult for children at this age. The reading comprehension score analysis can support this argument. This picture book had the lowest mean comprehension score.

\section{Regression Analysis to Predict Reading Comprehension}

Finally, the research analyzed the extent to which children's phonetic skills, character recognition, the first stage reading fluency, PPVT, and second stage reading score could explain reading comprehension using stepwise multiple regression analysis. The result showed only the first stage reading fluency and vocabulary comprehension entered the prediction equations. The two variables collectively explained approximately $45 \%$ of the variance in reading comprehension. The standardized regression coefficient $\beta$ value for the two independent variables were $.525(\mathrm{p}=.001), .329(\mathrm{p}=.032)$, reached a significant level. The $\beta$ values were positive which indicated that they are positive influences on reading comprehension skills before children entering primary school (See Table 6).

\section{Discussion}

Based on the above findings, the researcher believed that the results of this study are significant and meaningful in the controversial debate. Over-emphasis on phonetic skills in the preschool stage is not helpful in picture-book reading fluency for young children. Especially, reading fluency is a strong predictor for later reading comprehension. By spending most of time in decoding, the phonetic readers loss their train of thoughts while reading the text. Thus, their phonetic skill becomes an obstruction in comprehending. In addition, the study also found vocabulary comprehension to be a significant predictor in reading comprehension. Therefore, the researcher suggests parents and teachers should spend more time in help preschool children in Chinese character recognition and vocabulary comprehension, instead of focusing on the learning of Zhuyin Fuhao. In other words, parents and teachers should engage in meaningful reading with young children. This view is coincided with the whole language approach.

The study also found that there are four types of readers in the early stage of reading. The balanced readers performed best in reading comprehension. However, this finding was not consistent across all types of text. Therefore, more studies should be conducted to find a more conclusive explanation. Also, many questions emerged from the study. When children get older, will they stick to their early reading strategy or change to another type? What causes the change? 
Does the text style matter in young readers' reading comprehension? What text style should be introduced for Chinese readers in the early stage of reading to help promote their reading confidence and interests?

For future research, longitudinal studies should be conducted to follow subjects until third or fourth grade, when Zhuyin Fuhao is no longer used in all textbooks in Taiwanese primary schools. Therefore, it is important to find out how and what causes the change of reading style, if it occurs. They are two types of Chinese writing system, the traditional and simplified. Therefore, cross-regional studies should be conducted to compare whether different writing system has different miscue types. Finally, the study found that the narration style of picture books played an important role of young children's reading comprehension. More picture book studies should be conducted to make contributions in classroom reading practice in early childhood education.

\section{Acknowledgements}

This project was sponsored by Taiwan's Ministry of Science and Technology. Project number: NSC 99-2410-H-024-016

\section{REFERENCES}

[1] Adams, M. J. (1990). Beginning to read: Thinking and learning about print. Cambridge, MA: MIT Press.

[2] Almazrout, K. M. (2007). Learning together through restospective miscue analysis: Salem's case study. Reading Improvement, 44 (3), 153-168.

[3] Anbar, A. (1986). Reading acquisition of preschool children without systematic instruction. Early Childhood Research Quarterly, 1, 69-83.

[4] Betty, L. \& Care, E. (2009). Learning from their miscues: Differences across reading ability and text difficulty. Australian Journal of Language and Literacy, 32(3), 226-244.

[5] Cassidy, J., \& Cassidy, D. (2004, December/2005, January). What' hot, What's not for 2005. Reading Today, 22(3), 1, 8 .

[6] Cassidy, J. \& Ortlieb, E. (2013). The evolution of what's hot in literacy. e-Journal of Balance Reading Instruction, 1(2), 12-17.

[7] Cochran-Smith, M. (1984). The making of a reader. Norwood, NJ: Ablex Publishing Company.

[8] Eldredge, J. L. (2005). Foundations of fluency: An exploration. Reading Psychology, 26(2), 161-181.

[9] Farrington, P. (2007). Using context cues: Children as reading detectives. Literacy Today, June, 8-9。

[10] Goodman, K. (1969). "Analysis of oral reading miscues: Applied psycholinguistics". In F. Gollasch (Ed.) Language and literacy: The selected writings of Kenneth Goodman (pp.123-134). Vol. I. Boston: Routledge \& Kegan Paul.

[11] Goodman, Y. M. \& Goodman, K. S. (2004). To err is human:
Learning about language processes by analyzing miscues. In R.B. Ruddell, \& E.J. Unrau (Eds.), Theoretical models and processes of reading. (5th ed.). Newwark: International Reading Association.

[12] Goodman, Y. M., Watson, D. J., \& Burke, C. L. (2005). Reading miscue inventory: From evaluation to instruction. New York: Richard. C. Owen Publishers.

[13] Green, J. L. \& Harker, J. O. (1982). Reading to children: A communicative process. In J. A. Langer \& M. T. Smith-Burke (Eds.), Reader meets author/Bridging the gap: A psycholinguistic perspective.(pp. 196-221). Newark: D. E. International Reading Association.

[14] Haussler, M. M. (1982). Transition into literacy: A psycholinguistic analysis of beginning reading in kindergarten and first grade children. Unpublished doctoral dissertation. University of Arizona.

[15] Kabuto, B. (2009). Parents and children reading and reflecting together: The possibilities of family restrospective miscue analysis. The Reading Teacher, 63(3), 212-221.

[16] Machado, J. M. (2007). Early Childhood Experiences in Language Arts: Early Literacy. Belmont, CA: Wadsworth.

[17] Ninio, A. (1980). Picture book reading in mother-infant dyads belonging to two subgroups in Isreal. Child Development, 51, 587-580.

[18] Rossman, F. (1980). Preschoolers' knowledge of the symbolic function of written language in storybooks. Unpublished doctoral dissertation. Boston University.

[19] Spiegel, D. L. (1992), Blending whole language and systematic direct instruction. The Reading Teacher, 46(1), $38-44$.

[20] Sulzby, E. \& Anderson, S. (1982). The teacher as adult linguistic and social model. Paper presented at the International Reading Association. Chicago.

[21] Sulzby, E (1981). Kindergarteners begin to read their own compositions: Beginning readers' developing knowledge about written language project. Final report to the Research Foundation of the National Council of Teachers of English. Evanston, IL. Northwestern University.

[22] Sulzby, E. (1985a). Children's emergent reading of favorite storybooks: A developmental study. Reading Research Quarterly, 20(4), 58-81.

[23] Sulzby, E. (1985b). Kindergarteners as writers and readers. In Farr, M. (Ed.). Advances in Writing Research, volume I: Children's early writing development (pp.127-2000). Norwood, NJ. Ablex.

[24] Teale, W. H. (1981). Parent reading to their children. What studies of early readers tell us. Language Arts, 58, 902-910.

[25] Torrey, J. (1969). Learning to read without a teacher: A case study. Elementary English, 46, 550-556.

[26] Wang, C. (2002). Use of Informal Reading Assessment in Identifying First-Graders At-Risk Reading Disabilities. Journal of Taipei Municipal Teachers College, 33, 327-344.

[27] Wren, S. (2008). Reading and the three cueing systems. Retrieved from http://www.sedl.org/reading/topics/cueing.html 